\title{
Bridging the Achievement Gap for Low-Performing Students Using Computer-Adaptive Instruction
}

\author{
Haya Shamir, David Pocklington, Kathryn Feehan, and Erik Yoder
}

\begin{abstract}
Prior research into computer-assisted instruction (CAI) has demonstrated that the use of technology in the classroom has the potential to help underperforming young learners. The literature has also stressed that thorough evidence-based testing is needed to ensure that effective instruction is provided to students and that accurate information is available to educators. This study explored the effect of an adaptive CAI program on learning outcomes for young students. Kindergarten and first grade students used the Waterford Early Learning Program (WEL), a computer-adaptive reading curriculum, and were assessed at the beginning and end of the 2016-2017 school year. Analysis of gains found that students in both grades who used WEL benefited from significantly greater growth in literacy skills than a historic dataset of students from the previous year who did not use WEL. Students who used WEL outperformed their control counterparts on end of year scores despite having lower beginning of year scores on most strands. In this study, WEL improved the literacy scores of the students who used it, indicating that computer-assisted instruction can make a positive impact on students' early literacy skills.
\end{abstract}

Index Terms-Computer-adaptive curriculum, young learners, literacy.

\section{INTRODUCTION}

In 2000, the National Reading Panel established procedures for establishing the most effective, evidence-based instructional methods to teach children how to read [1]. These procedures have encouraged researchers to evaluate early childhood education with only high-quality studies, and to peruse stronger, more valid designs including replicating successful prior research [2]. Almost two decades later, technology is close to inseparable from learning - as a digital society, we are no longer discussing how to incorporate technology into the classroom, but how to most effectively utilize the technology present in all aspects of the classroom [3]. Early elementary school students not only need to learn how to read to excel in school, but how to sharpen their digital literacy skills to thrive in their daily lives and future workplaces. If a student does not learn to read by early elementary school, negative effects are pervasive into higher levels of education [4].

Technology can now not only reach students in one classroom, it can highly impact learning across states and across the country, shown through the ever-increasing enrollment in virtual courses [5]. A recent literature review of

Manuscript received May 18, 2018; revised November 15, 2018.

The authors are with the Waterford Research Institute, Sandy, UT 84093 USA (e-mail: hayashamir@waterford.org, davidpocklington@waterford.org, kathrynfeehan@waterford.org, erikyoder@waterford.org).
40 research studies involving elementary school students learning through technology found a medium effect size across studies $(g=0.55)$, implying that technology is an effective way for young students to learn [6]. Additionally, preschool students significantly outperformed control counterparts on emergent literacy skill strands following use of electronic book activities [7]. One potential way to include technology in the classroom is through computer-assisted instruction (CAI). CAI is an educational method of presenting students with different forms of interactive and instructional media. Unlike traditional large group instruction, CAI allows individual students to experience content that is consistently appropriate for their pace of learning and provides meaningful feedback [8]. Using an individualized curriculum increases students' flexibility, interactivity, and engagement, and it has been shown to improve young students' literacy skills [9]. CAI has been shown to benefit students at an early age: A study across 18 preschools gave students access to touchscreen desktops with interactive software which taught reading skills, and students who used the software scored higher in a standardized literacy test than those who did not [10].

Students from differing populations can also benefit from technology: Blended learning approaches have been found to succeed in early elementary school grades and across demographics such as students from low socioeconomic backgrounds and EL students [11]. For example, in one study, teaching sight words to students with intellectual disabilities in teacher-directed versus computer-assisted instruction lead to similar results, but students preferred the teacher-directed method [12]. Efforts to improve general education classrooms through effective instruction and interventions will assist all students, including students with disabilities [13]. In a study involving students from low-income backgrounds, students were randomly assigned to receive either CAI math instruction or CAI literacy instruction; at the end of the study, students who used the CAI math program significantly outperformed their reading counterparts on posttest math measures [14]. Additionally, students from low-income backgrounds improved comprehension skills and vocabulary when supplemented with a CAI literacy program compared to students who did not use the program [15].

Early education is key to students' success: High-quality pre-kindergarten programs are extremely important for students' academic trajectory and success in the classroom, especially for students from low-income families [16]. Unfortunately, new technologies alone may not be effective in closing achievement gaps despite allowing students more flexibility in their learning [5]. Students increasingly prefer to read digital texts as opposed to texts in print, yet their 
absorption of the material is less effective when reading digital texts [17]. Conclusions of published studies of technology programs can potentially be tailored to promote the programs rather than informing the educational sector [18]; moreover, studies are rarely replicated to add to the evidence-based educational research base and investigate the rigor and success of completed educational studies [2]. In order to respond to the demand for stronger research from almost two decades ago by the National Research Panel, research into the ever-growing field of educational technology is necessary to assist all students by providing access to evidence-based, quality practices and curricula.

In this study, students in the experimental group used a CAI literacy program in addition to their traditional classroom instruction, whereas the control group solely had traditional literacy in-class instruction. The hypothesis is that students who used a blended learning approach will outperform their control counterparts on all end of year literacy assessment strands.

\section{METHODS}

\section{A. Participants}

This study consisted of kindergarten and first grade students $(N=345)$ in a Tennessee school district. For kindergarten, the experimental group $(n=88)$ included students who used the Waterford Early Learning Program (WEL) during the 2016-2017 school year. The control group $(n=100)$ included students who attended kindergarten the previous year and did not use WEL. For first grade, the experimental group $(n=78)$ included students who used WEL during the 2016-2017 school year. The control group ( $n=79$ ) included students who attended first grade the previous year and did not use WEL.

\section{B. Materials}

\section{1) Waterford early learning program (WEL)}

The program offers a comprehensive, computer-adaptive pre-reading and reading curriculum for kindergarten through second grade students. The software presents a wide range of multimedia-based activities in an adaptive sequence tailored to each student's initial placement and his or her individual rate of growth throughout the complete reading curriculum.

2) Northwest evaluation association (NWEA) measures of academic progress (MAP)

The MAP is a valid assessment intended to measure individual growth and mastery for students in kindergarten through twelfth grade on a range of skills. The skills considered relevant to kindergarten and first grade students for this study are Foundational Skills, Language and Writing, Literature and Information, and Vocabulary Use and Functions. Results are scored on a standardized Rasch Unit (RIT) scale.

\section{Procedure}

Kindergarten experimental students were expected to use WEL for fifteen minutes per day, five days per week, and first grade experimental students were expected to use WEL for thirty minutes per day, five days per week. Usage was tracked within the program and monitored weekly, and total minutes of WEL usage for the school year per experimental group was calculated. Students in the control group received traditional literacy instruction for the same amount of time that the experimental group received CAI instruction. Thus, overall exposure to literacy instruction was the same for all groups. A literacy assessment was administered to all students at the beginning and end of the their respective school year.

\section{RESULTS}

\section{A. Kindergarten}

1) Group differences using Independent samples $t$-tests

Independent samples $t$-tests examining group differences in beginning of year and end of year scores between the experimental group and the control group were conducted (see Fig. 1 and 2).

\section{2) Group differences using analysis of covariance (ANCOVA)}

ANCOVAs examining group differences in end of year scores, covarying for beginning of year scores, between the experimental and control groups were conducted (see Fig. 3).

\section{a) Overall RIT}

Analysis of Overall RIT end of year scores, covarying for beginning of year scores, revealed a significant difference between groups, $F(1,185)=22.36, p<.01$, due to the higher end of year scores made by the experimental students $(M=$ $167.68)$ than by the control students $(M=156.96)$. Effect size $(d=0.66)$.

\section{b) Foundational skills}

Analysis of Foundational Skills end of year scores, covarying for beginning of year scores, revealed a significant difference between groups, $F(1,184)=23.61, p<.01$, due to the higher end of year scores made by the experimental students $(M=170.68)$ than by the control students $(M=$ 157.25). Effect size $(d=0.68)$.

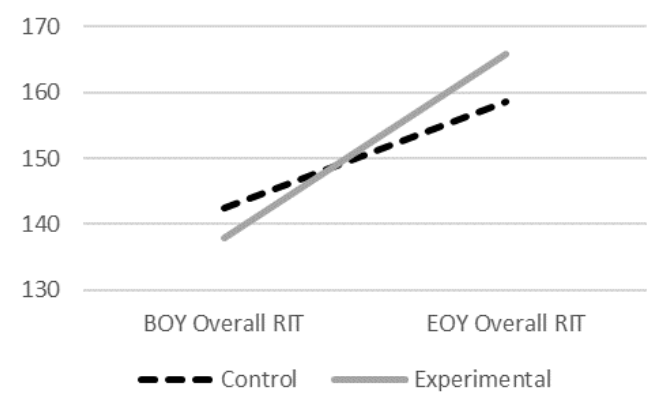

Fig. 1. Kindergarten beginning and end of year overall RIT scores.

\section{c) Language and writing}

Analysis of Language and Writing end of year scores, covarying for beginning of year scores, revealed a significant difference between groups, $F(1,185)=16.30, p<.01$, due to the higher end of year scores made by the experimental students $(M=165.29)$ than by the control students $(M=$ 155.83). Effect size $(d=0.58)$.

d) Literature and information 
Analysis of Literature and Information end of year scores, covarying for beginning of year scores, revealed a significant difference between groups, $F(1,185)=11.16, p<.01$, due to the higher end of year scores made by the experimental students $(M=165.95)$ than by the control students $(M=$ 158.25). Effect size $(d=0.47)$.

e) Vocabulary use and functions

Analysis of Vocabulary Use and Functions end of year
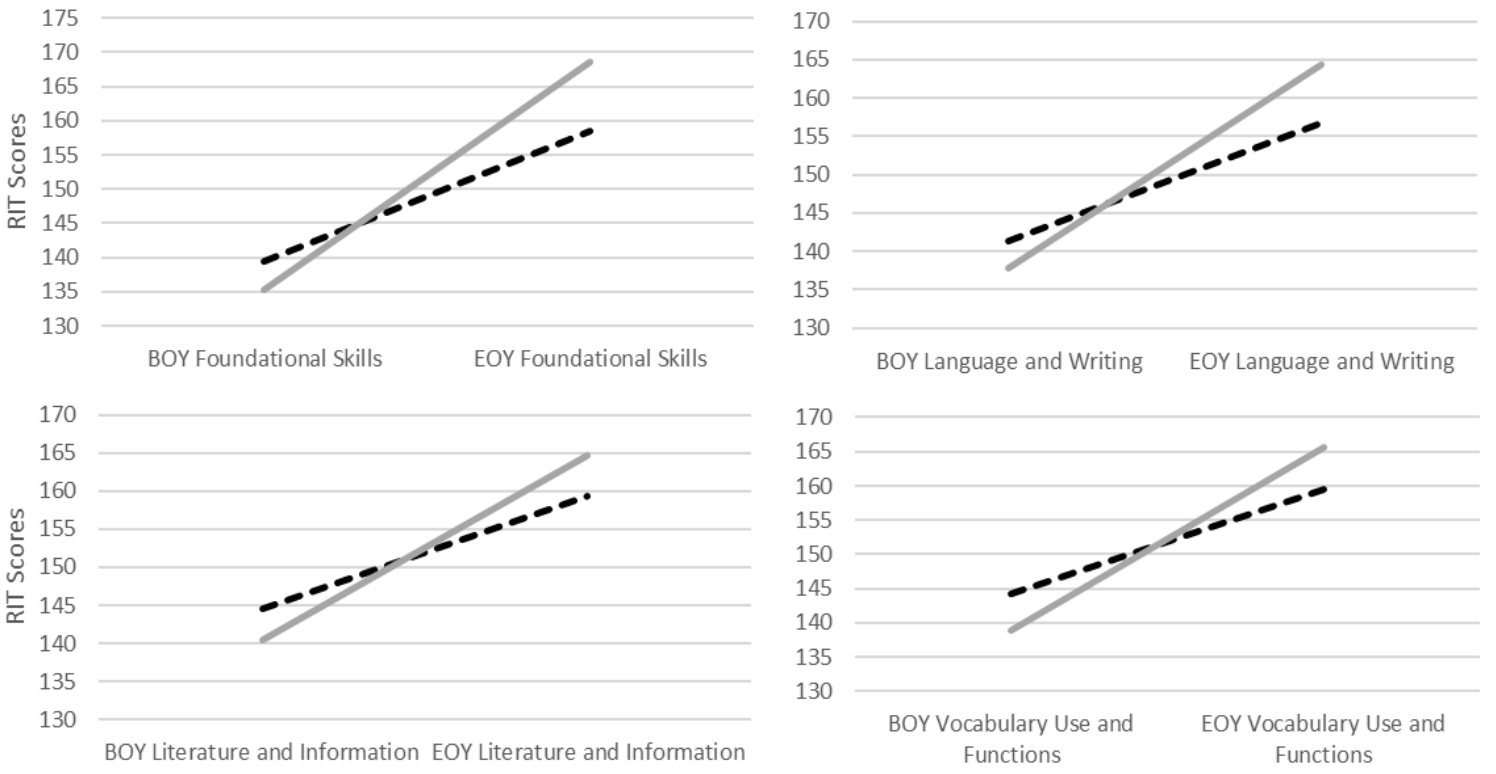

Fig. 2. Kindergarten beginning and end of year RIT scores by strand.

\section{B. First Grade}

\section{1) Group differences using independent samples t-tests}

Independent samples $t$-tests examining group differences in beginning of year and end of year scores between the experimental group and the control group were conducted (see Fig. 4 and 5).

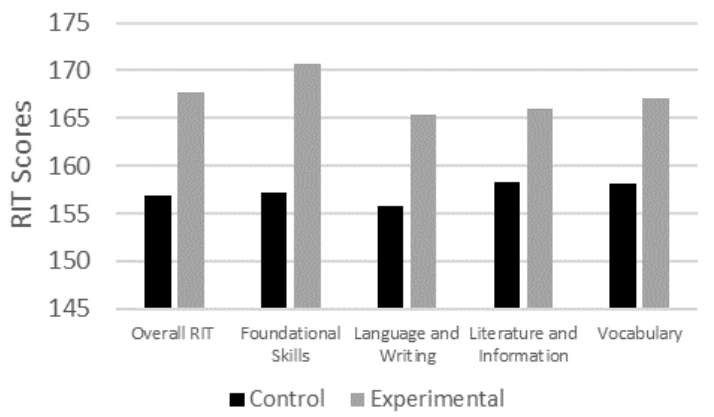

Fig. 3. Kindergarten end of year RIT scores while covarying for beginning of year scores.

\section{2) Group differences using analysis of covariance} (ANCOVA)

ANCOVAs examining group differences in end of year scores, covarying for beginning of year scores, between the experimental and control groups were conducted (see Fig. 6).

\section{a) Overall RIT}

Analysis of Overall RIT end of year scores, covarying for beginning of year scores, revealed a significant difference between groups, $F(1,154)=17.02, p<.01$, due to the higher scores, covarying for beginning of year scores, revealed a significant difference between groups, $F(1,185)=12.21, p$ $<.01$, due to the higher end of year scores made by the experimental students $(M=167.13)$ than by the control students $(M=158.22)$. Effect size $(d=0.51)$. end of year scores made by the experimental students $(M=$ $178.48)$ than by the control students $(M=170.09)$. Effect size $(d=0.55)$.

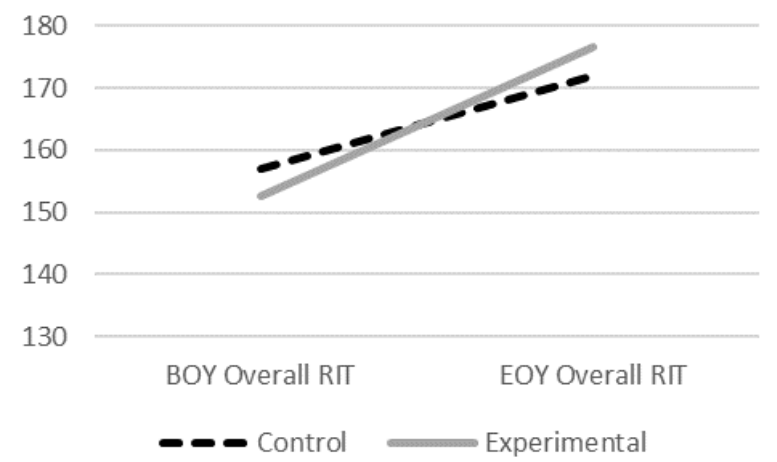

Fig. 4. First grade beginning and end of year RIT scores.

\section{b) Foundational skills}

Analysis of Foundational Skills end of year scores, covarying for beginning of year scores, revealed a significant difference between groups, $F(1,154)=26.31, p<.01$, due to the higher end of year scores made by the experimental students $(M=182.46)$ than by the control students $(M=$ 168.87). Effect size $(d=0.73)$.

c) Language and writing

Analysis of Language and Writing end of year scores, covarying for beginning of year scores, revealed a significant difference between groups, $F(1,154)=4.08, p<.05$, due to the higher end of year scores made by the experimental 
students $(M=176.75)$ than by the control students $(M=$
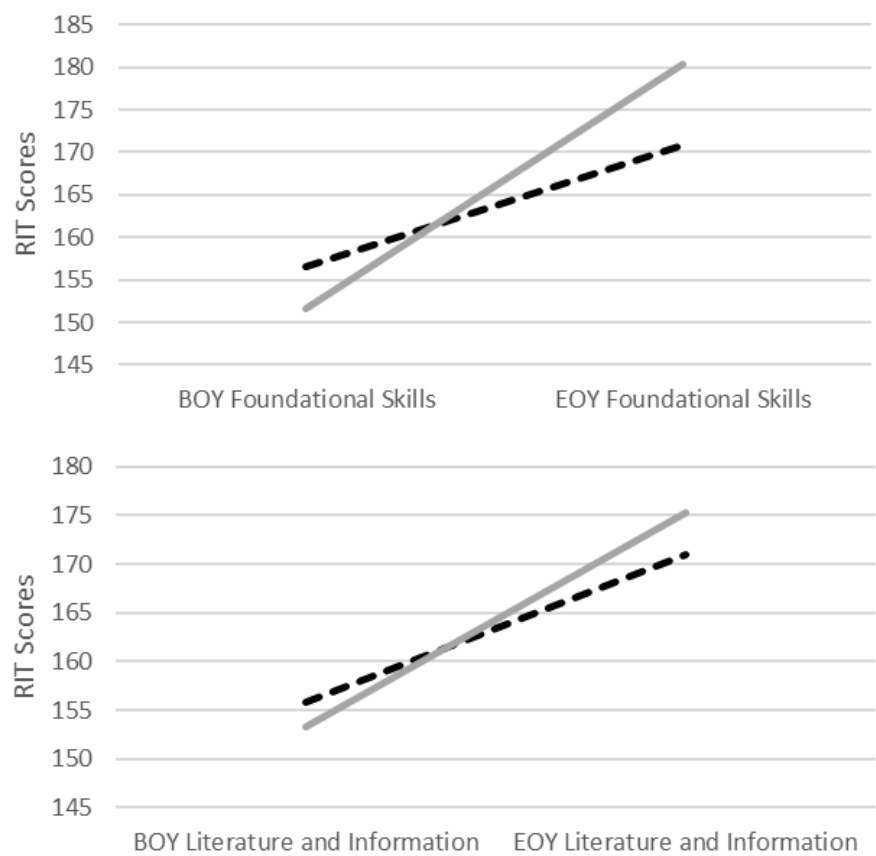

171.53). Effect size $(d=0.30)$.

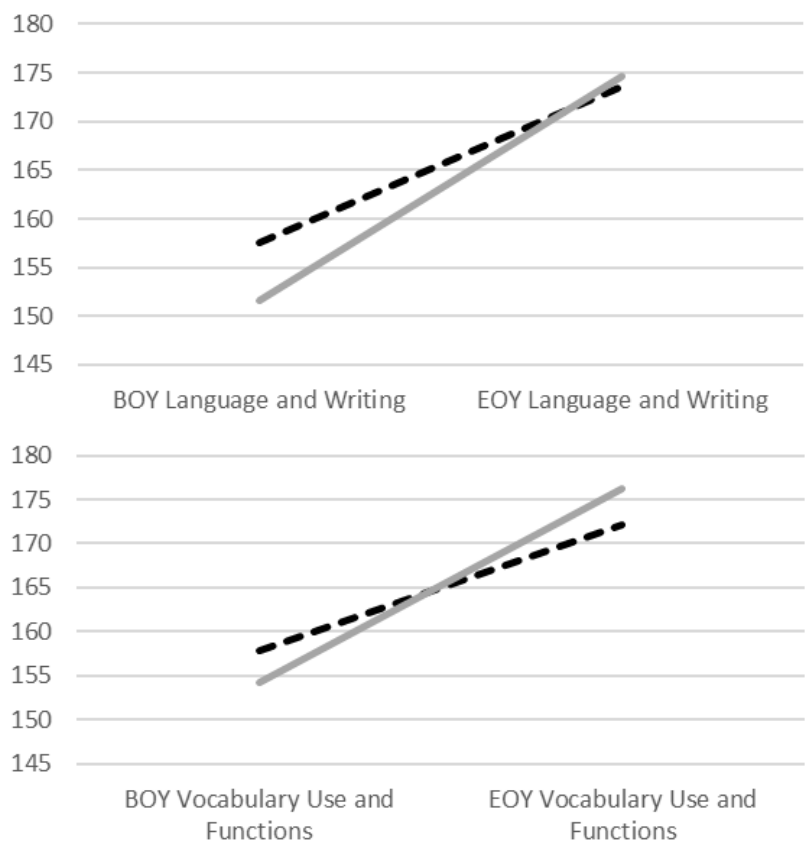

Fig. 5. First grade beginning and end of year RIT scores by strand.

\section{d) Literature and information}

Analysis of Literature and Information end of year scores, covarying for beginning of year scores, revealed a significant difference between groups, $F(1,154)=7.70, p<.01$, due to the higher end of year scores made by the experimental students $(M=176.11)$ than by the control students $(M=$ 170.09). Effect size $(d=0.38)$.

\section{e) Vocabulary use and functions}

Analysis of Vocabulary Use and Functions end of year scores, covarying for beginning of year scores, revealed a significant difference between groups, $F(1,154)=9.00, p$ $<.01$, due to the higher end of year scores made by the experimental students $(M=177.29)$ than by the control students $(M=171.03)$. Effect size $(d=0.42)$.

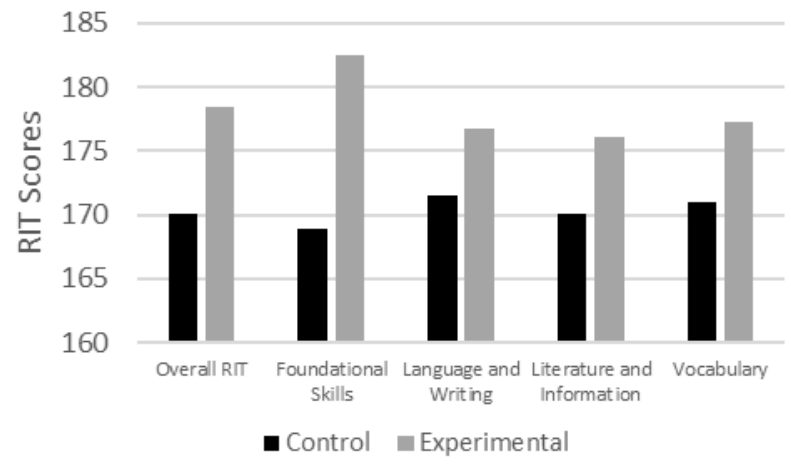

Fig. 6. First grade end of year RIT scores while covarying for beginning of year scores.

\section{CONCLUSION}

The current study explored the effect of a comprehensive, computer-adaptive curriculum on the literacy skills of young learners. The findings support the hypothesis: Despite having lower scores at the beginning of the year, students in both grades who used CAI technology consistently outperformed their control counterparts on all literacy assessment strands at the end of the year. For students in kindergarten and first grade, use of a computer-assisted curriculum lead to significantly higher end of year scores, while covarying for beginning of year scores, than scores by students who had traditional literacy instruction alone.

Effect sizes, as described by Cohen's conventions [19], ranged from small to medium. The largest effect sizes were for Foundational Skills for both kindergarten $(d=0.68)$ and first grade $(d=0.73)$. This was also the only circumstance where an effect size for first grade exceeded the effect size for the same strand in kindergarten. whereas both grades saw significant benefit from using the curriculum, effect sizes were larger for kindergarten than for first grade, with the largest discrepancy between Language and Writing for first grade $(d=0.30)$ and kindergarten $(d=0.58)$ : The larger effect sizes for kindergarten make a compelling argument for the early implementation of a computer-adaptive curriculum.

Some technical limitations of the current study should be acknowledged. The study had a largely homogenous sample in terms of ethnicity and lacked a meaningful sample of students with learning disabilities or English language learners. This limits the generalizability of the study and its ability to speak directly to what potential benefit a computer-adaptive curriculum may have for the most vulnerable students. Participants were from a single school district, which creates the possibility that local economic, geographic, or cultural confounds may have inadvertently influenced results. Additionally, the current study lacks longitudinal data and, as a result, cannot explore the longevity of any benefit gained from a computer-adaptive 
curriculum.

\section{REFERENCES}

[1] National Reading Panel (US), National Institute of Child Health, Human Development (US), "Report of the national reading panel: Teaching children to read: An evidence-based assessment of the scientific research literature on reading and its implications for reading instruction: Reports of the subgroups," National Institute of Child Health and Human Development, National Institutes of Health, 2000.

[2] M. C. Makel and J. A. Plucker, "Facts are more important than novelty: Replication in the education sciences," Educational Researcher, vol. 43, no. 6, pp. 304-316, Aug. 2014.

[3] K. Deady. (May 2017). Preparing students for a digital future: How teachers can bring digital literacy into the classroom. Teachaway. [Online].

Available: https://www.teachaway.com/blog/preparing-students-digital-future-ho w-teachers-can-bring-digital-literacy-into

[4] J. Graham and S. Kelly, "How effective are early grade reading interventions? A review of the evidence," Policy Research Working Paper; No. 8292, World Bank, Washington, DC, January 2018.

[5] B. Jacob, D. Berger, C. Hart, and S. Loeb, "Can technology help promote equality of educational opportunities?" RSF: The Russell Sage Foundation Journal of the Social Sciences, vol. 2, no. 5, pp. 242-271, Oct. 2016.

[6] S. Chauhan, "A meta-analysis of the impact of technology on learning effectiveness of elementary students," Computers \& Education, vol. 105, pp. 14-30, Feb. 2017.

[7] F. M. Ihmeideh, "The effect of electronic books on enhancing emergent literacy skills of pre-school children," Computers \& Education, vol. 79 , pp. 40-48, Oct. 2014.

[8] O. O. Jethro, A. M. Grace, and A. K. Thomas, "E-learning and its effects on teaching and learning in a global age," International Journal of Academic Research in Business and Social Sciences, vol. 2, no. 1, pp. 203-210, Jan. 2012.

[9] M. E. Stetter and M. T. Hughes, "Computer-assisted instruction to enhance the reading comprehension of struggling readers: A review of the literature," Journal of Special Education Technology, vol. 25, no. 4, pp. 1-16, Dec. 2010.

[10] M. H. McManis and L. D. McManis, "Using a touch-based, computer-assisted learning system to promote literacy and math skills for low-income preschoolers," Journal of Information Technology Education: Research, vol. 15, pp. 409-429, Jan. 2016.

[11] J. E. Prescott, K. Bundschuh, E. R. Kazakoff, and P. Macaruso, "Elementary school-wide implementation of a blended learning program for reading intervention," The Journal of Educational Research, vol. 111, no. 4, pp. 497-506, Apr. 2017.

[12] M. B. Coleman, R. A. Cherry, T. C. Moore, Y. Park, and D. F. Cihak, "Teaching sight words to elementary students with intellectual disability and autism: A comparison of teacher-directed versus computer-assisted simultaneous prompting," Intellectual and Developmental Disabilities, vol. 53, no. 3, pp. 196-210, June 2015.

[13] K. Hebbeler and D. Spiker, "Supporting young children with disabilities," The Future of Children, vol. 26, no. 2, pp. 185-205, 2016.

[14] M. E. Foster, J. L. Anthony, D. H. Clements, J. Sarama, and J. M. Williams, "Improving mathematics learning of kindergarten students through computer-assisted instruction," Journal for Research in Mathematics Education, vol. 47, no. 3, pp. 206-232, May 2016.

[15] B. Makhoul, E. Olshtain, and R. Ibrahim, "Let's read together: A balanced computer assisted intervention program and its effect on comprehension amongst at linguistic risk Arab first graders," Journal of Advances in Linguistics, vol. 5, no. 2, pp. 626-645, Feb. 2015.

[16] J. Brooks-Gunn, L. Markman-Pithers, and C. E. Rouse, "Starting early: Introducing the issue," The Future of Children, vol. 26, no. 2, pp. 3-19, Oct. 2016.

[17] P. Alexander, and L. Singer. (October 2017). The power of print in a digital world. $C N N$. [Online]. Available: https://www.cnn.com/2017/10/06/health/print-education/index.html

[18] T. Boulhrir, "Twenty-first century instructional classroom practices and reading motivation: Probing the effectiveness of interventional reading programs," International Journal of Education and Literacy Studies, vol. 5, no. 3, pp. 57-66, Jul. 2017.

[19] J. Cohen, Statistical Power Analysis for the Behavioral Sciences, Hillsdale, NJ: Lawrence Earlbaum Associates, 1988, ch. 2, pp. 20-26.

Haya Shamir was born Haifa, Israel. She received her $\mathrm{PhD}$ from University of Notre Dame in 2002. She has been working at Waterford Research Institute based in Sandy, Utah since 2005, currently serves as chief scientist. She has published research in multiple journals throughout her career.

David B. Pocklington was born in Southfield, MI, 1987. He graduated with the MS, Experimental Psychology, Rivier University, Nashua, NH, 2014. He currently works as a research assistant for the Waterford Research Institute, Sandy, UT. Research interests include computer-assisted instruction and assessment.

Kathryn C. Feehan was born in York, Pennsylvania. She graduated with honors from the University of Pittsburgh with a bachelor of science in psychology and sociology, and she is currently working on her master of science in education at Duquesne University. She currently works at Waterford Research Institute based in Sandy, Utah.

Erik H. Yoder was born in Greenwich, Connecticut, USA. He earned a bachelor of arts in psychology and Norwegian from St. Olaf College, Northfield Minnesota, USA, in 2012. He is employed as a research assistant at the Waterford Research Institute, based in Sandy, Utah, USA. 